\title{
El actual contexto ambiental en el Perú y la nueva Ley Forestal y de Fauna Silvestre*
}

Rosa Barrios Collantes

Abogada por la Universidad Nacional Mayor de San Marcos. Máster en el Marco Internacional en la Gestión, Acceso y Conservación de Especies en Comercio por la

Universidad Internacional de Andalucía. Máster en Conservación de Recursos Forestales por la Universidad Nacional Agraria. Miembro Fundador de la Red Latinoamericana de Derecho Forestal Ambiental.

SUMARIO:

I. Antecedentes.

II. La nueva ley forestal y de fauna silvestre.

III. Conclusión.

El presente artículo fue presentado por la Dra. Barrios ante el VIII Congreso Latinoamericano de Derecho Forestal Ambiental, realizado en San José de Costa Rica del 26 al 28 de octubre de 2011. 


\section{ANTECEDENTES}

Los años 70 fueron, en relación a los temas ambientales en el Perú, ricos en progresos tangibles -en comparación con los 80- ya que en esa década aun cuando el país era liderado por un gobierno militar, se había revisado y perfeccionado la base legal sobre recursos naturales renovables, creándose sistemas importantes como el Sistema Nacional de Unidades de Conservación, o aprobándose una serie de Convenios Internacionales de particular importancia como, por ejemplo, la Convención CITES.

Posteriormente, marcados por el retorno de la democracia, a través de las gestiones de los presidentes constitucionales Fernando Belaúnde Terry y Alan García Pérez, los años 80 fueron difíciles para el manejo del medio ambiente y de los recursos naturales; precisamente, en esos años se consolidó la primera década de vigencia de una de las leyes forestales y de fauna silvestre de mayor duración y, probablemente, la más discutida de la historia peruana: el Decreto Ley 21147.

En los años 90, época en que fue rediseñada la administración pública ambiental, se perfeccionó la legislación y se incrementó sustancialmente el número de áreas protegidas. En esta década, se creó el Instituto Nacional de Recursos Naturales - INRENA, y se caracterizó por ser muy prolíica en materia legislativa, ya que, en ella, se publicó el Código de Medio Ambiente y los Recursos Naturales (actualmente, derogado), la Ley de Áreas Naturales Protegidas, la Ley Orgánica para el Aprovechamiento Sostenible de los Recursos Naturales, la Ley sobre la Conservación y Aprovechamiento Sostenible de la Diversidad Biológica, entre otras importantes normas ambientales.

En el año 2000, luego de una vigencia de 25 años del Decreto Ley 21147, el Congreso de la República aprobó la Ley 27308 - Ley Forestal y de Fauna Silvestre que introdujo un nuevo sistema de acceso al bosque: las concesiones y las subastas públicas (estas últimas hasta la fecha no han sido implementadas).

Esta norma que fue reglamentada al año siguiente, tuvo una vigencia de 8 años, luego de los cuales fue derogada por el controversial Decreto Legislativo 1090, el que no solo no fue discutido ni consensuado con la población o siquiera sometido a consulta, sino que además provocaron los deplorables acontecimientos sucedidos en la provincia de Bagua (región de Amazonas), en donde la población de la localidad del mismo nombre y policías se enfrentaron, ocasionado pérdidas de vidas que no solo dejaron a familias huérfanas, además, nos brindó una amarga lección de lo que hoy en día implica en el Perú emanar normas inconsultas que afectan a poblaciones que, en gran medida, viven en su totalidad de lo ofrecido por el bosque. Esta norma tuvo que ser derogada y la vigencia de la Ley 27308 del año 2000, fue recobrada.

Solo un mes antes de estos hechos que marcaron un antes y un después en los conflictos socio-ambientales en el Perú, el Gobierno Peruano había creado el Ministerio del Ambiente, a través del Decreto Legislativo 1013, elevando al más alto nivel político la discusión de temas ambientales en el país y afianzando así, el compromiso de todos los peruanos frente a nuestros recursos naturales.

Sin embargo, cabe aquí precisar que la creación de este Ministerio, a su vez fue parte del compromiso que el Perú asumió como parte del Acuerdo de Promoción Comercial con los Estados Unidos de América, en cuyo Protocolo de Enmienda, más conocido como "Anexo Forestal", se requería reforzar la institucionalidad ambiental.

\section{LA NUEVA LEY FORESTAL Y DE FAUNA SILVESTRE}

Justamente otro de los compromisos asumidos en ese Acuerdo tiene relación con la revisión del ordenamiento legal vigente que regula el sector forestal en el Perú, lo que conllevó no solo a la modificación del Código Penal y la consecuente elevación de las penas por perpetrar delitos contra la ecología, sino también la dación de una nueva Ley Forestal y de Fauna Silvestre.

Es así que el 22 de julio de 2011, siete días antes del inicio de un nuevo período de Gobierno a la cabeza del nacionalista Ollanta Humala Tas- 
so, se publicó la nueva Ley Forestal y de Fauna Silvestre, mediante Ley 29763.

Si bien la norma no entrará en vigencia sino hasta que su Reglamento esté aprobado, cabe resaltar que uno de los principales cambios que introduce la norma es la creación del Servicio Nacional Forestal y de Fauna Silvestre (SERFOR), como la nueva autoridad nacional forestal y de fauna silvestre. El SERFOR reemplazará a la que hoy es la Dirección General Forestal y de Fauna Silvestre y la novedad es que el SERFOR estará dirigido por un consejo directivo integrado por doce representantes, entre los cuales se encuentran no solo entidades gubernamentales sino también miembros de la sociedad civil.

\section{CONCLUSIÓN}

El Sistema Nacional de Gestión Forestal y de Fauna Silvestre (SINAFOR); la Comisión Nacional Forestal y de Fauna Silvestre (CONAFOR); $y$, el Comité de Gestión Forestal y de Fauna Silvestre son parte de la nueva institucionalidad que nos ofrece esta nueva ley, en un contexto anual con matices importantes como el proceso de descentralización hacia los gobiernos regionales, el proceso de ordenamiento territorial y por qué no los constantes y cada vez más crecientes conflictos sociales, que según lo reportado por la Defensoría del Pueblo, más de la mitad están asociados a temas de recursos naturales y ambiente. 